\title{
Running an effective community mental health team
}

\author{
Swaran P. Singh
}

Community psychiatric teams are an integral part of modern mental health services. The development of such teams has allowed the care of patients to be transferred from institutions to the community. A Cochrane review of community-based programmes showed that community team-based psychiatric services led to a reduction in suicide rates, improved patient engagement and were more acceptable to patients (Tyrer et al, 1999). Community care also reduces the number of days patients stay in hospital, but not the number of admissions (Marshall et al, 1995). However, community mental health teams (CMHTs) have been criticised for their ambiguous and overambitious aims, and their tendency to neglect people with the most challenging health- and socialcare needs (Patmore \& Weaver, 1991; Sayce et al, 1991). All mental health workers are not necessarily eager, or skilled, to work effectively in teams. Building and maintaining an effective team requires commitment, clarity of purpose, a shared vision and frequent review of team operations. In a previous issue of $A P T$, Burns \& Guest (1999) described the adaptation and running of an assertive community treatment team in an inner-city area. Here I examine the attributes of effective CMHTs (Box 1), enumerate barriers and challenges to team-working (Box 2) and suggest strategies for improving team effectiveness (Box 3).

\section{Attributes of an effective community team}

What constitutes an effective team? Certain common themes emerge from the literature, as summarised in the following model of team effectiveness:
Box 1 Attributes of an effective team

Principles

Local and accessible

Comprehensive

Effective, efficient and responsive

\section{Structure}

Adequately resourced

Genuinely multi-disciplinary

Explicit work plans, objectives, review and monitoring systems

Comprehensive database

Consumer oriented

Culturally appropriate

Functions

Meets population needs, including special needs

Ensures good practice and use of effective interventions

Meets legal requirements

Assesses and manages risks

Good inter-agency liaison

\section{Coordination of functions}

Well led

Adequate knowledge of local resources

Proactive in a changing environment

Explicit management structure and accountability procedures

Maintains staff moral, professional development and team cohesion

Evaluates and audits processes and outcomes

Swaran P. Singh is the lead consultant in the Broxtowe and Northwest Mental Health Team within the Nottingham Healthcare NHS Trust (University Hospital, Nottingham NG7 2UH; tel: 0115924 9924; fax: 0115970 9709; e-mail: Swaran. Singh@nottingham.ac.uk). His research interests include onset, epidemiology and outcome of psychosis, acute psychotic disorders, ethnic influences in mental health and medical education. 
"An effective team would have clear, co-operative goals to which every member is committed; accurate and effective communication of ideas and feelings; distributed participation and leadership; appropriate and effective decision-making procedures; productive controversies; a high level of trust, acceptance and support among members; a high level of cohesion; constructive management of power and conflict; and adequate problem-solving procedures" (Anantraman, 1984).

Thorne (1992) identified seven fundamentals of effective teams: 'the seven Rs': raison d'etre, rules, roles, relationships, rituals, rewards and results. Teams outperform individuals acting alone, especially when performance requires multiple skills, judgements and experiences. Successful teams bring together complementary skills and experiences, thereby ensuring that team abilities are greater than the sum of individual abilities within the team (Box 1).

\section{Barriers to effectiveness}

\section{Inadequate resources}

Clinical- and cost-effectiveness are both influenced by the availability of adequate and appropriate resources. The 1980s saw a rapid reduction in the number of acute beds, prompted by the belief that a hospital-free psychiatric service could be provided in a cost-effective manner. The ideological position of 'few beds good, more beds bad' is flawed both in conception and in practice. Reducing length of stay from years to months, as happened in the case of those with long-term mental illness incarcerated in mental health hospitals, is not the same as reducing length of stay, for example, from 30 to 20 days. In addition, reducing inappropriate length of stay for a few patients is not the same as shortening the length of stay for everyone. Tyrer et al (1998) found that the advantages of community care were overshadowed by the unavoidable use of out-of-district admissions if local provision was inadequate. Beck et al (1997) demonstrated that even within a well-established community mental health service, there was often no alternative to admission for a large majority of patients admitted to acute wards. Adequate numbers of acute beds are therefore absolutely essential for the provision of effective mental health care.

\section{Lack of prioritisation and targeting of services}

Inter- and intra-team differences about which illnesses need to be targeted, how response should
Box 2 Barriers to effectiveness

\section{Structural}

Inadequate resources

Inter-professional differences, rivalries and power differential

Unclear lines of management

Poor inter-agency liaison

Functional

Resistance to change

Hierarchical $v$. horizontal decision-making processes

Failure to target services

Poor gatekeeping

Failure to prioritise response

Lack of throughput: failure to discharge stable cases and reluctance to take on complex, difficult to engage patients

Communication problems

Ideological commitment to models of care

Staff burn-out: worries about blameculture, management pressures

be prioritised and who should deliver care may lead to ineffective responses and fragmented services. Nationally, there are major differences between teams - in the range of services being provided, the proportion of long-term patient case-load and the management of workload (Onyett \& Smith, 1998). Similarly, marked variations exist between National Health Service (NHS) trusts, in the number of people subject to the Care Programme Approach (CPA), and supervision registers, which cannot be explained by variations in population needs alone (Bindman et al, 1999).

\section{Lack of throughput}

Backlog of chronic cases

The introduction of community services has not led to any major improvement in the outcome of disorders such as schizophrenia (Singh et al, 2000). The recurrent and relapsing nature of most mental disorders and the legislative requirement of ensuring engagement with those with a serious mental illness means that a backlog of long-term cases can quickly restrict the ability to take on new referrals.

\section{Difficult to engage patients}

Research evidence is often based on studies that exclude difficult to engage patients, especially those 
with dual diagnosis such as comorbid personality disorder, substance misuse or borderline learning disability. They tend to be young men with recurrent psychosis, with a history of violence, poor compliance and behavioural problems. Of the original Friern hospital long-stay patients, $15 \%$ were eventually designated as difficult to place in the community this is equivalent to a prevalence of 10-11/100 000 population in an area such as north London (Trieman, 1997). They are likely to slip through the net of care and are also the patients that team members are reluctant to take on for keyworking. The temptation, conscious or unconscious, of holding on to a fixed case-load of familiar cases can lead to acute services being log-jammed by chronic, stable cases.

\section{Poor gatekeeping}

Although general practitioners (GPs) themselves treat the bulk of minor psychiatric morbidity in the community, they, and often patients, prefer neurotic disorders to be treated by CMHTs (Gask et al, 1997). However, mental health teams are required to focus primarily on serious mental disorders. This discrepancy in the expectations of GP's and the actual capacity of mental health teams can lead to tension and conflict. Establishing community teams increases the referrals of neurotic disorders and personality disorders (Jackson et al, 1993) and does not by itself change the GPs' ability to detect and manage mental illness (Warner et al, 1993). Poor communication between GPs and psychiatrists (Strathdee \& Jenkins, 1996), an increasing demand for interventions such as counselling, and the blurred boundary between social pathology and mental illness at primary care level can lead to inappropriate demands being placed on mental health services.

\section{Democratic v. hierarchical decision-making}

A democratic and consensual form of decisionmaking, which respects and considers all opinions within the team, is usually considered an attractive model for multi-disciplinary work. However, laissezfaire climates are not the same as democracy. In a group with complete freedom for individual decisions, less work is done and it is often of poorer quality. Autocracy, on the other hand, can create hostility and aggression, as well as submissive behaviour. In a democratic group, teamwork and policies are a matter of group discussion and decision. Such groups promote creative ways of working, motivate members and improve morale. However, supposedly democratic teams can be oppressive if the power relations are concealed and consequently difficult to challenge (Lang, 1982). A non-hierarchical team functioning can hide dereliction of management and may serve to defend against the "intrusion of general management into the poorly defined arena of professional and clinical responsibility" (Onyett, 1997). Such flattened hierarchical structures can prevent effective functioning where failing services need to be overhauled or where there is a major difference of opinion, most likely to happen in difficult and complex cases where clear direction is vital.

\section{Ideological commitment to models}

Advocacy of a single paradigm/approach and ideological commitments to particular models of care can lead to rigid views and responses from team members. Debates and differences about care and control, civil liberties and health, biology and psychosocial influences, medication and psychotherapy etc., although reflecting differences in training and personal opinion, may also become implements of inter-personal battles in fragmented and conflict-ridden teams.

\section{Resistance to change}

Change is constant. Advances in medicine, better evidence for effective treatments, increasing pressure on dwindling resources, greater influence of advocacy groups and the 'post-Bristol' increase in media scrutiny will all ensure that services are constantly moulded in pursuit of greater clinicaland cost-effectiveness. One common individual and group response to such stressful change is a hardening of attitudes and a retreat into entrenched, obstructive positions that resist change. This can create an atmosphere of mutual suspicion between managers and clinicians, between different professional groups and between agencies, with a detrimental effect on services overall.

\section{Communication problems}

Lack of effective communication and poor coordination of care have been cited as the most important reasons for failures of care provision in some of the high-profile tragedies of 'failure of community care' (Ritchie, 1994; Davies, 1995). The Ritchie report commented on the overall inadequacy of communication, liaison and transfer of information between the numerous agencies involved in the care of 
Christopher Clunis. Poor communication is a major barrier to effective team operation and functioning.

\section{Staff burn-out}

Research programmes of community care rely heavily on staff committed to the aims of a usually well-resourced and time-limited trial (Coid, 1994). There has been concern that community care models, especially those providing intensive care, cannot be sustained over long periods of time because of their stressful impact on the staff. The term burn-out has been used to conceptualise the long-term negative effect of such stress and includes emotional exhaustion, tendency to develop cynical and negative attitudes towards others and negative self-evaluation, especially regarding personal accomplishment at work (Maslach \& Jackson, 1986). Such burn-out has been reported among both hospital and community staff, with higher levels in community mental health workers (Prosser et al, 1996). No one particular model of community care has been implicated, but working in inner-city areas produces the highest levels of stress (Wykes et al, 1997). A high level of staff turnover, rather than increasing burn-out, may lead to a greater sense of personal accomplishment among team members. However, high staff turnover has major implications for continuity of care for patients.

\section{Improving effectiveness}

\section{Adequacy of resources}

Inadequately resourced teams and services cannot hope to provide effective mental health care. Only when minimum standards of staff-patient ratios, representation of all relevant disciplines, availability of acute beds, after-care services and specialist services have all been met, can teams start developing action plans for improving effectiveness. Software packages such as MINI (Mental Illness Needs Index) recommend service requirements on the basis of population size and characteristics (Glover, 1996). However, as the Department of Health acknowledges, what the service users receive "is often more the reflection of historical circumstances, local service availability and provider priorities rather than need" (Department of Health/Social Services Inspectorate, 1993). Ideally, needs assessment should be based on both assumptions about service response, i.e number of acute beds, day places etc., and needs such as educational and vocational rehabilitation, activities of daily living and help with accommodation.
Box 3 Improving effectiveness

Adequacy of resources

Effective leadership

Shared view of team structures, organisation and function

Clear allocation of responsibility and explicit accountability procedures

Appropriate work allocation with equity of case-load

Developing and maintaining core skills:

(a) ability to identify mental disorders

(b) ability to assess and manage risk

(c) basic knowledge of psychotropic medication and its side-effects

(d) skilled use of educational strategies for patients and carers

(e) skills in improving compliance and engagement

Prioritising and targeting serious mental illness

Proactive outreach

Meeting legal requirements

Risk assessment and documentation

Shared learning with specialised training for specialist work

Regular team workshops

Improved liaison with primary care

Improving members' mental well-being

\section{Effective leadership}

Leadership is the capacity to cause others to follow. Based upon leadership styles, team leaders can be broadly divided into solo leaders and team leaders (Belbin, 1993). Solo leaders are directive, project objectives, strive for conformity and tend to collect acolytes. Such leadership style is perceived by others as interfering and authoritarian and can be destructive to team functioning. By contrast, the team leader ('first among equals') chooses to delegate roles, builds on diversity, seeks and nurtures talent, develops colleagues and projects a shared vision. Such leaders are less likely to claim personal credit for successes and will try to create opportunities for others. In a mental health team an effective leader provides good management, has a clear vision, understands local and national issues, is aware of group dynamics and is aware of the strengths and weaknesses of individual team members. Leadership need not necessarily be bestowed upon the consultant. Consultants will always have an implicit leadership role in any team because they 
are most likely to be asked for advice and guidance. Any perceived loss of autonomy in not taking up the leadership role is more than adequately compensated for by the sharing of difficult decisions, guarding clinical time from management meetings and mutual empowering of team members.

\section{Shared views of the team}

Within the team a shared view of definition, prioritisation, risk assessment, resource allocation and delegation of responsibility is vital to achieve effectiveness. Teams composed entirely of highly intelligent people do not always win in competitive situations because individual members may seek to persuade the others that their own approach is correct, rather than work towards a common goal. Such teams are prone to destructive debates, have difficulty making decisions and may spend more time in analysis and counter-analysis ('paralysis by analysis') than in the synthesis of ideas. While role differentiation is important, Belbin (1993) found that good teams were composed of individuals whose abilities led them to adapt easily to different roles. Such individuals varied their roles, timed their interventions appropriately, created roles for others and did some of the jobs avoided by others. Eligibility for a particular role by way of qualifications and experience does not necessarily reflect suitability, which requires aptitude, versatility and a 'role fit'. Personality clashes at work are often role clashes, and good teams avoid these by ensuring concordance between an individual team member's own assessment of his or her roles with assessments by other team members.

Team relationships and accountability mechanisms are best made explicit. The Sainsbury Centre Community Mental Health Team survey reported a general abdication of management responsibilities in teams (Onyett \& Smith, 1998). For 51\% of the teams surveyed, the team-as-a-whole had ultimate responsibility and consultants had most responsibility in only $2 \%$ the teams. A participatory style of management may cause accountability to be so diffuse as to be ineffective. Hence, although the team-as-a-whole consensual and democratic form of decision-making is a good usual mode of operation, a bottom-line hierarchy with a designated decision-maker is vital to ensure that individual professional responsibility is understood, conflicts resolved and difficult decisions made.

\section{Work allocation system}

Effective teams need a structured system for prioritising referrals and allocating work in an equitable manner. This requires a clear understanding of which illnesses need targeting, what constitutes risk, how it is best managed and who is best placed to provide such assessment. Table 1 shows prioritisation criteria that were developed following a workshop conducted by the Northwest and Broxtowe Mental Health Team in Nottingham. These criteria were later discussed with local GPs. An important section of the criteria dealt with inappropriate referrals where the team intervention was felt to be unnecessary or inappropriate. In our experience, such explicit understanding of what psychiatric services can and cannot provide led to a better response to referrals, improved targeting of resources and promoted better liaison with primary care. GPs' feedback suggested that they gained a better understanding of why our team did not provide services purely for social pathologies masquerading as mental illness, such as domestic violence.

The report of the National Confidential Inquiry, Safer Services, recommended that contact between patients and services must serve a specified agreed purpose (Appleby, 2000). Routine reviews of stable patients and duplication of work between team members is wasteful and may take resources away from patients with greater need or higher risk. In our experience, team reviews of long-term stable cases, or difficult to engage patients, where staff were encouraged to express uncertainty and doubt, while being provided guidance and supervision, served to improve both clinical practice and team morale.

\section{Developing and maintaining core skills}

Deinstitutionalisation relocated staff from institutes to community-based services without adequate training and preparation. Nationally, only half the trusts offer training in risk-assessment to nursing staff (Appleby, 2000). A Sainsbury Centre review suggested that if community care is to provide an effective and relevant service to patients, radical changes in staff training and education are necessary (Duggan, 1997). A minimum standard of core skills, including ability to identify mental disorders, assess and manage risk, basic knowledge of psychotropic medication and their side-effects, use of educational strategies with patients and carers and skills in improving compliance and engagement, should be expected of all team members. There is increasing demand from patients and carers for non-pharmacological therapies even for psychotic disorders. Skills such as psychological therapies and family interventions require specialist training. If 
Table 1 Prioritisation criteria referrals

\begin{tabular}{|c|c|c|c|}
\hline $\begin{array}{l}\text { Urgent } \\
\text { (within } 48 \text { hours) }\end{array}$ & $\begin{array}{l}\text { Soon } \\
\text { (within } 2 \text { weeks) }\end{array}$ & $\begin{array}{l}\text { Routine } \\
\text { (within } 2 \text { months) }\end{array}$ & Return referral \\
\hline $\begin{array}{l}\text { By diagnosis } \\
\text { Acute psychosis } \\
\text { Acute mania } \\
\text { Severe depression }\end{array}$ & $\begin{array}{l}\text { Moderate depression } \\
\text { Acute crisis } \\
\text { Chronic psychosis with } \\
\text { sub-acute deterioration } \\
\text { in mental state }\end{array}$ & $\begin{array}{l}\text { Long-standing } \\
\text { neurotic disorder } \\
\text { Personality disorder } \\
\text { with illness or distress }\end{array}$ & $\begin{array}{l}\text { Antisocial personality } \\
\text { disorder } \\
\text { Marital disharmony } \\
\text { Uncomplicated bereave- } \\
\text { ment, drug or alcohol } \\
\text { dependence, violent men } \\
\text { without comorbid mental } \\
\text { illness }\end{array}$ \\
\hline $\begin{array}{l}\text { By risk } \\
\text { Recent, or threat of, } \\
\text { harm to self/others } \\
\text { Past history of } \\
\text { violence, serious } \\
\text { self-harm or serious } \\
\text { offending behaviour }\end{array}$ & $\begin{array}{l}\text { At risk but contained } \\
\text { by family/carers }\end{array}$ & Absence of risk & $\begin{array}{l}\text { No at risk referrals will } \\
\text { be returned without } \\
\text { assessment }\end{array}$ \\
\hline $\begin{array}{l}\text { By socio-demographics } \\
\text { Isolated or no support } \\
\text { Dependent } \\
\text { children/elderly }\end{array}$ & $\begin{array}{l}\text { Chaotic family life } \\
\text { Carer distress }\end{array}$ & Supportive family & Patient not in our sector \\
\hline $\begin{array}{l}\text { By other clinical details } \\
\text { Supervision register }\end{array}$ & $\begin{array}{l}\text { Care Programme } \\
\text { Approach level } 2 \\
\text { Recent discharge } \\
\text { Awaiting discharge } \\
\text { Recent onset }\end{array}$ & $\begin{array}{l}\text { General practitioner } \\
\text { (GP) and patient } \\
\text { willing to wait }\end{array}$ & $\begin{array}{l}<16 \text { or }>65 \text { years old } \\
\text { Physical illness needs } \\
\text { to be ruled out in a non- } \\
\text { psychiatric hospital }\end{array}$ \\
\hline $\begin{array}{l}\text { By needs } \\
\text { May need } \\
\text { hospitalisation }\end{array}$ & $\begin{array}{l}\text { Recently stopped } \\
\text { medication }\end{array}$ & $\begin{array}{l}\text { GP requests 'routine } \\
\text { assessment' }\end{array}$ & Needs counselling only \\
\hline
\end{tabular}

training and supervision are inadequate, such therapies are less likely to be effective (Fadden, 1998). Thorn training courses, run at centres in London, Manchester and Nottingham, have been shown to improve nurses' effectiveness in delivering researchbased interventions in schizophrenia (Brooker et al, 1994). Joint case discussions and team-based journal clubs on evidence-based practice can enable interprofessional sharing of complementary perspectives and promote continuing professional development.

\section{Improved primary care liaison}

There is no research evidence to show greater effectiveness of any one particular model of primary and secondary care liaison, although Gask et al, (1997) consider the consultation-liaison model to have several theoretical advantages. At a minimum, GPs must be aware of sector boundaries, referral procedures, crisis provision, telephone access points, contact addresses and information booklets of therapies available within NHS and non-NHS services. A regular discussion of difficult cases, twoway feedback on communication problems (such as inadequate information in referrals or unnecessary detail in psychiatrists' letters) outreach clinics in GP surgeries and shared-care protocols all promote effective liaison.

\section{Proactive outreach for difficult to engage patients}

Generic CMHTs combine continuity of care, contact with the same care provider, flexibility and an indepth knowledge of local resources. There is no substantial evidence from the UK that more intensive models, such as those incorporating assertive community treatment (ACT) or intensive case management, are superior to basic CMHT care (Burns et al, 1999). A Cochrane review suggested that case management tended to increase admissions without a major advantage over standard care in any psychiatric or social outcome (Marshall et al, 1998). In addition, case management increased 
health care costs. Kent and Burns (1996) have described the advantages of incorporating ACT into community teams. Well-resourced teams can aim to provide assertive outreach care by adopting a philosophy of proactive and assertive engagement for difficult to engage patients. A service-wide strategy based upon CPA principles and involving GPs, carers and other professional agencies can be developed to ensure that patients are effectively monitored in the community, compliance is ensured and deterioration in mental health is detected early.

\section{Meeting legal requirements}

Teams need to ensure that they meet the legal requirements set out in the CPA and aftercare provision. Local application of CPA policy varies widely in the country and prioritisation is not closely based on need (Bindman et al, 1999). Further central guidance on CPA may emerge, along with legislation on community care orders and detention of individuals with an untreatable personality disorder. Meanwhile, teams require an agreed explicit understanding of keyworker roles and responsibilities, clear documentation of care plans that are accessible to other members during crises and effective inter-agency liaison. Designated CPA clinics in the community, distinct from routine follow-up clinics, may allow doctors the time necessary for detailed reviews and ensure participation of all relevant individuals.

\section{Regular team workshops and shared learning}

Focused team workshops and creative brainstorming sessions can allow free exchange of ideas and airing of contentious issues, some of which, if left to fester, will cause enduring resentment among members. In our experience, sharing of ideas on issues such as CPA provision, risk assessment, prioritisation of response and individual cases of untoward incidents improved team cohesion and helped generate better models of service delivery. We have found that team workshops are ideal to resolve interpersonal differences over team goals, methods and values and help turn potentially destructive conflicts into constructive, collaborative and learning exercises.

\section{Improving the team's health and well-being}

The main sources of stress for team members are threats to their efficacy owing to lack of resources, workload, bureaucracy and fear of a blame-culture in suicide and homicide cases. Clinical work itself is a major source of reward, as are contact with colleagues and multi-disciplinary working (Onyett \& Smith, 1998). There are several ways of dealing with such burnout. Fixed work schedules rather than flexitime (Fielding \& Weaver, 1994), stressmanagement training (Wykes et al, 1997), periodic secondments to other agencies and even simple recognition and airing of the problem are all useful.

\section{Conclusions}

Community mental health teams will continue to be the backbone of psychiatric services and we are unlikely to see the return of hospital-based care. Inadequate resources, especially the rapid reduction in acute bed numbers and pressures of bureaucracy, excessive and poorly managed workloads and the blame-culture have all made community working stressful, and in some cases ineffective. We should define what we do best by first emphasising what it is that we cannot do. Hence, a team consensus on targeting serious mental illness, using evidencebased practice and equity of case-load are vital to improve effectiveness. Undergraduate training of all mental health disciplines needs to be modified to ensure that basic knowledge and core skills necessary for providing effective mental health care can be developed early in the training.

\section{References}

Anantraman, V. (1984) Teambuilding. In Human Resource Management: Concepts and Perspectives (eds V. Anantraman, L. Chong, S. Richardson, et al). Singapore: Singapore University Press.

Appleby, L. (2000) Safer services: conclusions from the report of the National Confidential Inquiry. Advances in Psychiatric Treatment, 6, 5-15.

Beck, A., Croudace, T. J., Singh, S., et al (1997) The Nottingham acute bed use study: alternatives to acute psychiatric care. British Journal of Psychiatry, 170, 247-252.

Belbin, R. M. (1993) Team Roles at Work. Oxford: ButterworthHeinemann.

Bindman, J., Beck, A., Glover G., et al (1999) Evaluating mental health policy in England. Care Programme Approach and supervision registers. British Journal of Psychiatry, 175, 327-330.

Brooker, C., Falloon, I., Butterworth, A., et al (1994) The outcome of training community psychiatric nurses to deliver psychosocial intervention. British Journal of Psychiatry, 165, 222-230.

Burns, T. \& Guest, L. (1999) Running an assertive community treatment team. Advances in Psychiatric Treatment, 5, 348356.

- Creed, F., Fahy, T., et al (1999) Intensive versus standard case management for severe psychotic illness: a randomised trial. The Lancet, 353, 2185-2189. 
Coid, J. W. (1994) Failure in community care: psychiatry's dilemma. British Medical Journal, 308, 805-806.

Davies, N. (1995) Report of the Inquiry into the Circumstances Leading to the Death of Jonathan Newby. Presented to the Chairman of Oxford Regional Health Authority. London: HMSO.

Department of Health/Social Services Inspectorate (1993) Health of the Nation Key Area Handbook: Mental Illness. London: Department of Health.

Duggan, M. (1997) Pulling Together. London: Sainsbury Centre for Mental Health.

Fadden, G. (1998) Family intervention. In Serious Mental Health Problems in the Community. Policy, Practice and Research (eds C. Brooker \& J. Repper), pp. 159-183. London: Balliere Tindall.

Fielding, J. \& Weaver, S. (1994) A comparison of hospital and community based mental health nurses' perception of their working environment and psychological health. Journal of Advances in Nursing, 19, 1196-1204.

Gask, L., Sibbald, B. \& Creed, F. (1997) Evaluating models of working at the interface between mental health services and primary care. British Journal of Psychiatry, 170, 6-11.

Glover, G.R. (1996) Using the Mental Illness Needs Index Programme. London: Department of Public Health and Primary Care, Charing Cross and Westminster Medical School.

Jackson, G., Gater, R., Goldberg, D., et al (1993) A new community mental health team based in primary care. A description of the service and its effects on service use in the first year. British Journal of Psychiatry, 162, 375-384

Kent, A. \& Burns, T. (1996) Setting up assertive community treatment service. Advances in Psychiatric Treatment, 2, 143150 .

Lang, C. L. (1982) The resolution of status and ideological conflicts in a community mental health setting. Psychiatry, 45, 159-171.

Marshall, M., Lockwood, A. \& Gath, D. (1995) Social services case management for long-term mental disorders: a randomised controlled trial. Lancet, 345, 409-412.

-_-, Gray, A., Lockwood, A. \& Green, R. (1998) Case management for people with severe mental disorders. The Cochrane Library, 2.

Maslach, C. \& Jackson, S. (1986) Maslach Burnout Inventory (2nd edn). Oxford: Oxford Psychologists Press.

Onyett, S. (1997) The challenge of managing community mental health teams. Health and Social Care in the Community, 5, 40-47.

- \& Smith, H. (1998) The structure and organisation of community mental health teams. In Serious Mental Health Problems in the Community. Policy, Practice and Research (eds C. Brooker \& J. Repper), pp. 62-86. London: Balliere Tindall

Patmore, C. \& Weaver, T. (1991) Community Mental Health Teams: Lessons for Planners and Managers. London: Good Practices in Mental Health.

Prosser, D., Johnson, S., Kuipers, E., et al (1996) Mental health, 'burnout' and job satisfaction among hospital and community-based mental health staff. British Journal of Psychiatry, 169, 334-337.

Ritchie, J. H. (1994) The Report of the Inquiry into the Care and Treatment of Christopher Clunis. London: HMSO.

Sayce, L., Craig, T. K. J. \& Boardman, A. P. (1991) The development of community mental health centres in the UK. Social Psychiatry and Psychiatric Epidemiology, 26, 14-

Singh, S. P., Croudace, T., Amin, S., et al (2000) Three-year outcome of first-episode psychoses in an established community psychiatric service. British Journal of Psychiatry, 176, 210-216.

Strathdee, G. \& Jenkins, R. (1996) Purchasing mental health care for primary care. In Commissioning Mental Health Services (eds G. Thornicroft \& G. Strathdee), pp. 71-84. London: HMSO.

Thorne, P. (1992) Hit Squads. International Management, 47, 56.
Trieman, N. (1997) Patients who are too difficult to manage in the community. In Care in the Community: Illusion or Reality? (ed J. Leff), pp. 175-188. Chichester: John Wiley \& Sons.

Tyrer, P., Evans, K., Gandhi, N., et al (1998) Randomised controlled trial of two models of care for discharged psychiatric patients. British Medical Journal, 316, 106-109.

- Coid, J., Simmonds, S., et al (1999) Community mental health teams for people with severe mental illnesses and disordered personality. The Cochrane Library, 4.

Warner, R. W., Gater, R., Jackson, M. G., et al (1993) Effects of a community mental health service on the practice and attitudes of general practitioners. British Journal of General Practice, 43, 507-511.

Wykes, T., Stevens, W. \& Everitt, B. (1997) Stress in community care teams: will it affect the sustainability of community care? Social Psychiatry and Psychiatric Epidemiology, 32, 398-407.

\section{Multiple choice questions}

1. Community care of the mentally ill:

a has led to increase in suicide rates

b reduces number of admissions to hospital

c is more acceptable to patients

d improves patient engagement

e has been criticised for its ambiguous aims.

2. Stress in community teams:

a is associated with inner-city working

b is helped by periodic secondments to other agencies

c is worse for flexitime workers than those in fixed schedules

d is worsened by staff turnover

e is associated with particular models of community care.

3. Effective leaders:

a should be directive

b are less likely to claim personal credit for success

c seek conformity within the team

d have a laissez-faire attitude

e are authoritarian.

4. In the UK:

a over two-thirds of mental health trusts offer nursing staff training in riskassessment

b variations in Care Programme Approach policy across regions is owing to variations in population needs

c case management has not been shown to be significantly superior to standard community care

d most community mental health teams are consultant-led

e service development has been 'needs-led'. 
5. Effective teams:

a have clear role differentiation

b utilise a democratic form of decisionmaking

c have a participatory and diffuse management structure

d have explicit accountability mechanisms

e are composed of individuals who prefer detailed analysis of problems to synthesis of ideas.

MCQ answers

$\begin{array}{lllll}1 & 2 & 3 & 4 & 5\end{array}$

a $\mathrm{F}$ a $\mathrm{T}$ a $\mathrm{F}$ a $\mathrm{F}$ a $\mathrm{T}$

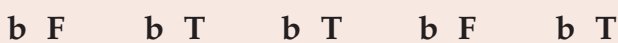

c $T$ c $T$ c $F \quad$ c $T$ c $F$

d T d F d F d F d T

e $\begin{array}{llllll}T & \text { e } F & \text { e } F & \text { e } F & \text { e } F\end{array}$

\section{Safety in Psychiatry The Mind's Eye}

A new video learning pack containing:

- video 'The Mind's Eye'

- training notes to accompany the video (20 copies per pack)

- tutors' notes

This film provides everyday examples of threatening incidents which doctors can readily identify with. The high quality production techniques combined with atmospheric location work and use of real stories combine to give the film an immediacy that ensures high observer involvement.

The film has an engaging commentary by psychiatrist and broadcaster, Professor Anthony Clare.

Improving safety awareness is more about how people think about situations than about memorising information. Focused small-group discussion triggered by carefully selected and memorable case examples is therefore likely to be the most effective way of developing safety awareness, especially when this is reinforced by a systematic approach to safe practice as laid out in the accompanying booklet.

Although best used in combination with tutor-led small-group discussion, the film and the accompanying booklet are self-contained, and could be used as resource material in a library or self-learning room.

\section{September 2000, £75.00, ISBN 1901242560}

Book Sales, The Royal College of Psychiatrists, 17 Belgrave Square, London SW1X 8PG.

Tel: +44 (0)20 72352351 ext. 146; Fax: +44 (0)20 72451231

The latest information on College publications is on the Internet at www.rcpsych.ac.uk 